\title{
Meer vrouwen in het openbaar bestuur: lessen uit de publieke sector
}

\author{
Saniye Çelik
}

'Er zijn blijkbaar nog te veel mechanismen die vrouwen afschrikken of waardoor mannen toch weer kiezen voor mannen. Daarom is dat quotum zo belangrijk.'

Mariëtte Hamer, voorzitter Sociaal-Economische Raad (Trouw 28 december 2019)

'Diversiteit is een zaak van ons allemaal, zoals ook de politiek dat is sinds 1919.'

Francine Giskens, collegelid Algemene Rekenkamer tijdens discussieforum over diversiteit (toespraak Algemene Rekenkamer, 12 december 2019)

\section{Inleiding}

In 2019 was het honderd jaar geleden dat vrouwen in Nederland kiesrecht kregen. Een mooie aanleiding om de huidige positie van vrouwen in politieke en bestuurlijke functies te peilen. Recente onderzoeksrapporten beschrijven vooruitgang, maar constateren ook dat het tempo waarin de toename zich voltrekt, laag is. De Sociaal-Economische Raad (SER) oordeelde dan ook dat het de hoogste tijd is voor een versnelling en adviseerde dat de raden van commissarissen van beursgenoteerde bedrijven voortaan minimaal voor 30 procent uit vrouwen moeten bestaan (SER, 2019). Een meerderheid in de Tweede Kamer was het daar mee eens en wil dat het kabinet zo'n vrouwenquotum invoert. Een recent onderzoek laat zien dat bindende quota leiden tot een snellere toename van vrouwen aan de top dan in landen zonder streefcijfers (Jongen e.a., 2019). Naast genderdiversiteit in de top van organisaties groeit de aandacht voor etnische diversiteit in organisaties. Volgens de gangbare definitie van het Centraal Bureau voor Statistiek (CBS) verwijst etnische diversiteit naar een persoon die zelf of van wie een van de ouders geboren is in het buitenland. In zijn recente rapport beveelt de SER (2019) specifiek overheidsbeleid aan voor de doorstroom van deze groep, een aanbeveling die minder aandacht heeft gekregen in de media en de politiek dan die over de vrouwenquota. De adviezen rond gender- en etnische diversiteit zijn weliswaar voornamelijk voor het bedrijfsleven en (semi)publieke sector geformuleerd, maar ze gelden evengoed voor adviescolleges van de regering en politieke en publieke functies. De Kaderwet adviescolleges uit 1997 stelt dat gestreefd wordt naar evenredige deelname van vrouwen en mensen met een migratieachtergrond. Als de adviescolleges een afspiegeling zouden vormen van de maatschappij, zou de manvrouwverdeling 50 procent zijn en het aandeel leden afkomstig uit een etnische of culturele minderheid 24 procent. Op basis van recent onderzoek toont de Alge-

* $\quad$ Dr. Saniye Çelik is lector diversiteit aan de Hogeschool Leiden, decaan inclusief leiderschap bij het NSOB en opleider bij Center for Professional Learning aan de Universiteit Leiden. 
mene Rekenkamer (2019) aan dat het aantal vrouwen in adviescolleges van de regering sinds 2010 toeneemt. Anno 2019 staat de teller op 38 procent. Maar het aandeel etnische diversiteit is gedaald: van 10 procent in 2016 naar 4 procent in 2019. In tabel 1 staan de huidige percentages vrouwen en mensen met niet-(volledig)Nederlandse wortels in bestuur en politiek:

Tabel 1 Vrouwen en etnische minderheden in de politiek en het openbaar bestuur, 2020, in procenten*

\begin{tabular}{lll}
\hline Politiek-openbaar bestuur & Vrouwen & Etnische diversiteit \\
\hline Regering & 39 & $4 * *$ \\
Tweede Kamer & 33 & 13 \\
Eerste Kamer & 39 & 1 \\
$\begin{array}{l}\text { Commissarissen van de } \\
\text { Koning }\end{array}$ & 8 & 0 \\
Gedeputeerden & 28 & 2 \\
Provinciale statenleden & 35 & 5 \\
Dagelijks bestuur water- & 25 & 0 \\
schappen & 29 & \\
Burgemeesters & 27 & 1 \\
Wethouders & 32 & 2 \\
Raadsleden & & $6-13^{* * *}$ \\
\hline
\end{tabular}

* De getallen zijn verzameld via internet, bijvoorbeeld afkomstig van de sites www.rijksoverheid.nl en www.parlement.com. De percentages vrouwen zijn deels ontleend aan het onderzoek van De Jong en Leyenaar (2019). Bij etnische diversiteit is geteld op basis van de achternaam. Ook de personen met een Nederlandse achternaam van wie bekend is dat ze niet(volledig)Nederlandse wortels hebben, zijn meegeteld. Zoals de Tweede Kamerleden Jesse Klaver, Vera Bergkamp, Steven van Weyenberg, Niels van den Berge, Klaas Dijkhof. Desondanks is het gepresenteerde percentage slechts een indicatie: Naar verwachting kan er maximaal een afwijking zijn van I procent.

** Minister Kajsa Ollongren heeft Zweedse wortels.

*** 13 procent is een inschatting gebaseerd op het gemiddelde van een recent onderzoek in opdracht van Raadslid.nu (Akachar, 2019). Van negen gemeenten zijn de raadsleden met een migratieachtergrond in beeld gebracht. De percentages luiden: Amsterdam 3I, Tilburg 6, Eindhoven 6, Leiden 13, Dordrecht 13, Purmerend 9, Zaandam 14, Culemborg 14, Voorst 8. De reële inschatting voor het landelijke gemiddelde ligt veel lager. Volgens een rapport van het ministerie van BZK bedroeg in 2016 het percentage raadsleden met een migratieachtergrond 6 procent.

Dit is de stand anno 2020, ondanks de tientallen jaren van inzet van de Nederlandse overheid om meer diversiteit binnen het openbaar bestuur te bewerkstelligen. Of het nu gaat om de ambtelijke top of om politieke functies, nagenoeg alle onderdelen van de publieke sector zeggen enerzijds de ongelijkheid tussen mannen en vrouwen te willen wegwerken en anderzijds de verschillen te benutten om de effectiviteit van de overheid te vergroten. En deze inzet heeft wel enig effect gehad. Maar wie tabel 1 bekijkt, kan niet anders dan constateren dat we er nog lang niet zijn. En dus luidt de noodklok: de stijging van het aantal vrouwen in het openbaar bestuur blijkt het laatste decennium traag te gaan en zelfs enigszins af te vlakken (Kamerstukken II 2019/20, 30420, 328). De jarenlang gehanteerde 
streefcijfers voor vrouwen in topfuncties binnen de publieke sector en de maatregelen voor etnische diversiteit hebben weliswaar iets opgeleverd - de top van de rijksoverheid en de politie telt ruim 40 procent vrouwen -, maar dat is niet voldoende. Slechts één op de twaalf commissarissen van de Koning is vrouw. Een radicale aanpak met quota lijkt de oplossing. Niets doen is geen optie, want dan is de kans groot dat het aantal vrouwen in topposities stagneert.

De politiek en het openbaar bestuur kunnen het goede voorbeeld geven, ze kunnen de functie van vliegwiel gaan vervullen in de discussie over de gewenste aantallen vrouwen in hun gelederen. Minister Ollongren van Binnenlandse Zaken en Koninkrijksrelaties (BZK) heeft in dit verband aan de Tweede Kamer een pakket maatregelen gepresenteerd, verdeeld over drie sporen. Het eerste gaat over het bevorderen van inclusieve werving-en-selectieprocedures, en trainingsmodules die dit ondersteunen. Het tweede leidt naar het actief uitnodigen van vrouwen om deel te nemen aan het openbaar bestuur. Een maatregel is bijvoorbeeld het oriëntatieprogramma voor mensen die een stap naar het politieke ambt van wethouder of burgemeester overwegen. En het derde spoor betreft een goede toerusting van het politieke ambt. Concrete maatregelen in dit kader zijn bijvoorbeeld inwerk- en opleidingsmogelijkheden, het onderzoeken van afhaakmotieven van politieke ambtsdragers door middel van een exitonderzoek, en het bevorderen van een inclusieve politieke cultuur met netwerken (Kamerstukken II 2019/20, 30420, 328).

Dit artikel reflecteert op het voorgestelde pakket aan maatregelen aan de hand van de lessen die voortvloeien uit de praktijk van ruim een halve eeuw diversiteitsbeleid bij de overheid en de inzichten uit de wetenschap. Maar laten we eerst de vraag beantwoorden waarom organisaties werk maken van diversiteit. Wat zijn de onderliggende motieven?

\section{Waarom diversiteit?}

Organisaties hanteren uiteenlopende motieven voor het bevorderen van diversiteit. Vier veelvoorkomende drijfveren zijn: gelijkheid, legitimiteit, creativiteit (Ely \& Thomas, 2001) en verbinding (Çelik, 2016). Bij het gelijkheidsmotief staat de morele plicht om te streven naar gelijkheid centraal. Niet zo verwonderlijk, want het gelijkheidsdenken is in Nederland impliciet aanwezig en vastgelegd in artikel 1 (antidiscriminatie) van de Grondwet. De overheid wil vanuit haar maatschappelijke verantwoordelijkheid én als grootste werkgever in Nederland (één miljoen werknemers) een voorbeeld zijn voor de private sector, teneinde rechtvaardigheid en emancipatie te stimuleren (Çelik, 2014). In een samenleving waarvan één op de twee mensen vrouw is, kan de top van bestuur en politiek niet voor het merendeel uit mannen bestaan. Het is daarom verklaarbaar waarom de meeste interventies binnen de overheid zich richten op het wegwerken van achterstanden van vrouwen en mensen met een migratieachtergrond. 
Het tweede motief is de legitimiteit van het overheidsapparaat, dat dient met andere woorden een afspiegeling te zijn van de samenleving. Dit geldt niet alleen voor de volksvertegenwoordiging, maar ook voor functies in verschillende lagen van de overheid waarin mensen kunnen meebeslissen over beleid en aanpak. Als we dit vertalen naar het lokaal bestuur, zien we dat burgers zowel de burgemeester als de wethouder, het raadslid en de ambtenaar beschouwen als het gezicht van de gemeente. Dit benadrukt het belang van een representatieve democratie, maar ook van een dito bureaucratie. Als de verschillende bevolkingsgroepen op die twee niveaus zijn vertegenwoordigd, kunnen hun waarden en normen een rol gaan spelen bij de beleidsontwikkeling. Het beleid sluit dan beter aan bij wat er leeft onder de bevolking en wordt door alle bevolkingsgroepen beter geaccepteerd dan wanneer hun stem niet doorklinkt (Sowa \& Selden, 2003). Als het lokaal bestuur een afspiegeling van de samenleving is, dan draagt dat bij aan het draagvlak voor en de herkenbaarheid van de politieke besluitvorming. Vertrouwen van burgers in het ambtelijk apparaat en in de politiek ligt ten grondslag aan het legitimiteitsmotief (Çelik, 2018).

Een derde motief is creativiteit, met als uitgangspunt dat verschillen kunnen bijdragen aan betere diensten en prestaties van een organisatie. Diversiteit wordt dan gezien als een businesscase om te komen tot innovatie in de bestuurlijke arena. Kennis, inzichten en vaardigheden van politici uit verschillende groepen (zowel meerderheid als minderheid) worden in de praktijk benut om bijvoorbeeld maatschappelijke vraagstukken op te lossen. Verschillen in etnische achtergrond, leeftijd en gender en de verschillende visies die hieruit ontspruiten, worden gezien als leermomenten voor nieuwe inzichten (Ely \& Thomas, 2001).

Dan het vierde motief, verbinding. Dit borduurt voort op alle hiervoor beschreven perspectieven. Het gaat verder dan de demografische weerspiegeling in de personeelssamenstelling en de bijdrage van diversiteit aan de effectiviteit van de overheid. Dit perspectief stelt dat het omgaan met de verschillen in de organisatie het leggen van verbindingen met de diversiteit aan burgers in de samenleving vergemakkelijkt. Het verbindingsmotief benadrukt de noodzaak actief te investeren in een duurzame relatie met de burger. Een opvallend onderscheid met de andere invalshoeken is dit: het omgaan met de verschillen is een issue van alle medewerkers, ongeacht hun etnische achtergrond. Allen worden geacht verbindingen te leggen met de diversiteit aan burgers in de samenleving. Dit motief uit zich in het centraal stellen van de voorbeeldfunctie, de dienstbaarheid van de overheid en daarmee samenhangend de tevredenheid van de burgers (Çelik, 2016). De toenemende cocreatie met ambtenaren, politici, burgers en maatschappelijke partners bij de ontwikkeling van beleid is hier een voorbeeld van.

De vier drijfveren hangen sterk met elkaar samen. Het ene motief sluit het andere niet uit en ze verbinden diversiteit aan de doelen van de organisatie. Helaas zien we in de praktijk vaak dat organisaties die met diversiteit aan de slag gaan deze motieven niet voldoende omzetten in concrete, effectieve interventies. Dit is een fundamentele fout, want het te ontwikkelen beleid en de daaruit voortvloeiende maatregelen horen gebaseerd te zijn op de motieven. Gebrek aan diversiteitsmo- 
tieven leidt in de praktijk vaak tot interventies die hun doel niet bereiken. Het een kan nu eenmaal niet zonder het ander.

\section{Van emancipatiebeleid naar meer vrouwen in het openbaar bestuur}

De emancipatie van vrouwen kent een lange historie. Precies een eeuw geleden kregen vrouwen in Nederland het kiesrecht, een niet te onderschatten uitkomst van de eerste feministische golf. Een halve eeuw later bracht Joke Smit eigenhandig de tweede golf in beweging met het artikel 'Het onbehagen bij de vrouw', gepubliceerd in De Gids (november 1967). Wakker geschud eisten vrouwen in de jaren die daarop volgden recht op betaald werk, op goede en betaalbare kinderopvang, op het recht om baas in eigen buik te zijn, op een eigen plek in de maatschappij, op - kortom - de voltooiing van de emancipatie. Niet alle vrouwen schaarden zich achter de actievoerders. Vonden ze te luidruchtig, te onbeschaafd omdat ze zich hulden in tuinbroeken en weigerden bh's te dragen, en ook omdat zijzelf hun bestaan als huisvrouw en moeder vanzelfsprekend vonden en (nog) geen behoefte voelden aan verandering. Maar successievelijk werd gehoor gegeven aan veel feministische eisen. Vanaf de jaren zeventig hebben de achtereenvolgende regeringen emancipatiebeleid gevoerd. Jeltien Kraaijeveld-Wouters (CDA) werd in 1977 de eerste staatssecretaris voor emancipatiezaken. In 1981 nam Hedy d'Ancona ( $\mathrm{PvdA}$ ) het stokje van haar over. In het huidige kabinet is het dossier verdeeld: minister Van Engelshoven van Onderwijs, Cultuur en Wetenschap is verantwoordelijk voor vrouwenemancipatie, met de toevoeging tussen haakjes 'gendergelijkheid', en minister Ollongren van Binnenlandse Zaken en Koninkrijksrelaties spant zich in voor meer vrouwen in het openbaar bestuur.

De passage hieronder illustreert hoe een van de eerste trekkers van het emancipatiebeleid in Nederland oordeelt over de huidige stand van zaken. Dit gesprek met Hedy d'Ancona (1937), exclusief ten behoeve van dit artikel, vond plaats op 30 december 2019. D'Ancona was van september 1981 tot mei 1982 staatssecretaris van Sociale Zaken en Werkgelegenheid en onder meer belast met het emancipatiebeleid.

\section{Hedy d'Ancona over de percentages vrouwen in het openbaar bestuur}

'De uitkomst is bedroevend'

Zwijgend luistert ze naar de opsomming van de percentages vrouwen op de diverse niveaus van het openbaar bestuur in Nederland. Dan reageert ze met teleurstelling in haar stem: 'Als je vijftig jaar geleden hebt vastgesteld dat de macht eerlijk verdeeld moet worden tussen vrouwen en mannen, dat onze wereld op die manier bestuurd en gestuurd dient te worden, dan is de uitkomst bedroevend. Zulke lage percentages vrouwen in het openbaar bestuur... we kunnen wel spreken van een mislukking. En dat terwijl het belangrijkste argument om vrouwen te weren van de plaatsen die hen toekomen - te lage opleiding - niet meer geldt, want het opleidingsniveau van 
vrouwen is stormachtig gestegen. Er studeren nu meer vrouwen dan mannen af aan hogescholen en universiteiten.'

Hedy d'Ancona kan haar misnoegen maar met moeite verbergen. 'In een democratische rechtsstaat als de onze is dat eigenlijk treurig. Daar komt bij', vervolgt ze, 'dat mannen met macht, gewoon geen zin hebben om vrouwen binnen te halen. Neem Rutte die bij de formatie van het huidige kabinet waarin geen sprake is van gelijke aantallen mannen en vrouwen zei: "We letten op kwaliteit." Ik vind dat een dubbele belediging.'

\section{Om en om m/v}

Er zijn wel degelijk mogelijkheden om de trage toename van vrouwen in het openbaar bestuur in een versnelling te brengen, vindt D'Ancona, zoals de invoering van quota die, zoals ze zegt, een voorbeeldfunctie kunnen hebben. Maar ook een maatregel als haar eigen partij heeft genomen: 'De Partij van de Arbeid heeft al tijden de gewoonte om op de kandidatenlijsten om en om een man en een vrouw te plaatsen. Dan maak je het waarschijnlijker dat er evenveel mannen als vrouwen worden gekozen. Weliswaar kan er dan bijvoorbeeld bij de formatie van een kabinet weer een totaal ander beeld ontstaan, maar het begin is er.' Dit voorbeeld zouden de andere partijen moeten volgen en dan voor alle bestuurslagen, van parlement tot gemeenteraad. 'Jammer genoeg bestaat het Kamerbreed Vrouwenoverleg niet meer, maar de vrouwen in de Tweede Kamer zouden dit bij hun partij kunnen bepleiten. Van de partijen die dit weigeren, is dan meteen duidelijk dat je van hen niets hoeft te verwachten op dit punt en er dus ook niet meer op hoeft te stemmen.'

Overigens starten de Rooie Vrouwen van de PvdA op 8 maart van dit jaar de D'Ancona-leergang voor vrouwen die een plaats ambiëren in het openbaar bestuur. 'Maar die plekken moeten dan wel gecreëerd worden', zegt de naamgever van de leergang.

\section{5-urige werkdag}

Terugkijkend op de ideeën die in de jaren zestig en zeventig van de vorige eeuw opkwamen om de macht eerlijk te verdelen, blijft er voor haar één fier overeind staan. 'Wij zeiden dat dit alleen maar mogelijk is als het werk in de privésfeer eerlijk wordt verdeeld, en dát kan alleen maar bij een 5-urige werkdag. Maar we zijn er helaas niet in geslaagd de arbeidstijden voor iedereen te reduceren. De meeste mannen hebben nu een volle baan, de meeste vrouwen een halve. Er is dus geen sprake van dat alle vrouwen economisch zelfstandig zijn, zoals de bedoeling is. Ik weet heus wel dat een 5-urige werkdag niet gemakkelijk is als je een functie in het openbaar bestuur vervult. Maar bestuurlijke banen zijn over het algemeen tijdelijk en vragen dus om een tijdelijke oplossing. Ook daarom zou het zoveel gemakkelijker zijn als de partner maar vijf uur per dag werkt.' 


\section{Lessen uit de publieke sector}

Ook al is de uitkomst van het emancipatiebeleid in Nederland niet altijd en overal zo effectief zoals veel voorstanders hadden verwacht, toch is er de afgelopen vijftig jaar in Nederland wel het een en ander ingezet op het gebied van genderdiversiteit. De ontevredenheid over de bereikte resultaten geldt vooral de trage vooruitgang. Dat blijkt ook uit de vorige paragraaf. Ondanks gebrek aan wetenschappelijk onderzoek naar wat wel en niet werkt, kunnen we toch lering trekken uit de praktijk van de publieke sector. Zie hier enkele lessen.

1. Meet de effectiviteit van maatregelen voor diversiteit in het openbaar bestuur De hiervoor beschreven motieven kunnen als kapstok fungeren voor interventies, en de richting wijzen bij het realiseren van de ambities. Dan doemt als eerste vraag op: wat is het voornaamste motief voor diversiteit in het openbaar bestuur? Als het antwoord luidt: om gelijkheid tussen mannen en vrouwen te stimuleren, dan past daar een aanpak met streefcijfers goed bij. Echter, als het motief het bevorderen van creativiteit en connectiviteit is, ligt een maatregel als cocreatie het organiseren van sessies waarbij de verschillende perspectieven van mensen meegenomen worden voor het oplossen van vraagstukken - meer voor de hand. Dit is relevant om de effectiviteit van de interventies te meten. Decennialang hebben publieke organisaties allerlei interventies ingezet, zoals doorstroomprogramma's voor vrouwen en personen met een migratieachtergrond of trainingen voor selectiecommissies. En zelden of nooit is gemeten wat deze interventies precies opleveren. Tegenwoordig is bijvoorbeeld het aanbieden van trainingen over onbewuste vooroordelen een hype, terwijl bekend is dat interventies gericht op bewustwording of het tegengaan van vooroordelen nauwelijks resulteren in gedragsverandering en zelfs averechts kunnen werken (Kaiser e.a., 2012).

\section{Kies voor een samenhangende aanpak}

De uitdaging voor publieke organisaties is om diversiteit niet als een tijdelijke en geïsoleerde actie te benaderen, maar als een organisatieveranderingsproces. Wie dat doet, koppelt diversiteit aan de algemene processen in de organisatie. Een dergelijke aanpak richt zich dan niet alleen op specifieke groepen. Dat wil niet zeggen dat er geen doelgroepgerichte programma's opgezet kunnen worden, maar eerder hoe de verschillende maatregelen in samenhang gebracht kunnen worden. Voor het openbaar bestuur worden in de Beleidsreactie rondetafelgesprek vrouwen in het openbaar bestuur door de minister van BZK stevige maatregelen met betrekking tot vrouwen voorgesteld (Kamerstukken II 2019/20, 30420, 328). Maar het is een gemiste kans om deze niet door te trekken naar verjonging en meer etnische diversiteit. Ook deze groepen zijn ondervertegenwoordigd. Alle maatregelen die de minister voorstelt, kunnen naar evenredigheid breder ingezet worden, vooral in grote gemeenten, waar soms één op de twee burgers van niet-Nederlandse origine is. 


\section{Besteed aandacht aan leiderschap en veranderende profielen}

Een succesvolle aanpak van diversiteit en inclusie staat of valt met goed leiderschap (Shore, Cleveland \& Sanchez, 2018). Dat geldt ook voor politici en bestuurders. De dynamiek in de publieke ruimte is aan verandering onderhevig en dat vraagt andere competenties van de leidinggevenden. Denk aan het verbindend en adaptief vermogen, dat tegenwoordig als een van de belangrijkste competenties geldt van politieke ambtsdragers (Raad voor het openbaar bestuur, 2016). Hoe weet je verbinding te houden met verschillende groepen in de samenleving? Vroeger huurde de gemeente iemand in om conflicten op te lossen. Tegenwoordig wordt van de burgemeester verwacht dat deze zelf beschikt over verbindend vermogen, inlevingsvermogen en coachend leiderschap om de toenemende verschillen in belangen en meningen te overbruggen en te verenigen (Çelik \& Hopman, 2018). Dit vraagt het steeds opnieuw toetsen van de competentieprofielen van politieke ambtsdragers. Daar hoort ook bij het diversiteitssensitief maken van deze profielen. Onderzoek toont aan dat neutrale profielen de aantrekkingskracht vergroten voor een bredere doelgroep.

Het valt zeker te prijzen dat de minister van BZK in de beleidsreactie op het rondetafelgesprek aangeeft de benoemingsprocedure Handreiking burgemeestersbenoemingen uit 2016 kritisch onder de loep te nemen. In deze handreiking wordt onder meer een advies opgenomen over gelijke man-vrouwverhoudingen in selectiecommissies en de bevordering van inclusieve selectie door middel van trainingen. Het staat de politieke partijen echter vrij dit advies wel of niet op te volgen. En daar zit de adder onder het gras: politieke partijen vervullen een spilfunctie bij de profielbeschrijvingen en de selectie van wethouders. Datzelfde geldt voor de selectie van gedeputeerden en bestuursleden van de waterschappen. De politieke partijen - van links tot rechts - spelen dan ook een cruciale rol bij het realiseren van meer diversiteit in politiek en bestuurlijk Nederland. De vraag is of zij bereid zijn deze rol op zich te nemen en hierover afspraken te maken.

\section{Neem werving-en-selectieprocedures kritisch onder de loep}

Door de tot nu toe gehanteerde selectiecriteria komen veel minder vrouwen dan mannen op vacatures af. De bereidheid om meer vrouwen in topposities aan te nemen blijkt onvoldoende te zijn. Daarom is het aanscherpen van profielen en de gevraagde competenties hard nodig. Datzelfde geldt voor de procedures, omdat vrouwen vaker benadeeld worden door genderstereotypen bij de werving en selectie, met als gevolg lagere inschatting en waardering dan mannen (Herschberg, 2019). Als we naar de werving van burgemeesters kijken, zien we dat men zich vaak richt op kandidaten die wethouder of burgemeester zijn (geweest). Onder hen bevinden zich weinig vrouwen, zoals tabel 1 aan het begin van dit artikel aantoont.

Onderzoek laat zien dat de kansen op diversiteit toenemen wanneer de sollicitatiecommissie divers is samengesteld: meer dan één vrouw, meer dan één persoon met een migratieachtergrond. Verschillende belemmerende mechanismen worden dan voorkomen, waaronder de zogenoemde onbewuste vooroordelen ofwel de groepsdruk die een rol speelt bij de selectie van kandidaten. Wanneer de 
selectiecommissie bestaat uit de leden van de meerderheidsgroep, dan ligt het 'soort zoekt soort'-mechanisme voor de hand.

Onderzoek van de Algemene Rekenkamer naar diversiteit bij adviescolleges van de regering leert ons dat werving vanuit het eigen netwerk van de organisatie niet per definitie tot diversiteit leidt. Wie zich bij vacatures richt op het kleine wereldje van personen die de organisatie al in het vizier heeft, loopt het risico de status quo in stand te houden. Dus is het nodig om een breed netwerk onder de loep te nemen. Bovendien is transparantie van vacatures noodzakelijk.

Voor alle sectoren van het openbaar bestuur geldt: vraag nadrukkelijk aan vrouwen en mensen met een niet-westerse achtergrond om te solliciteren. Dat is een strategie die loont. Ze staat niet voor niets op nummer 1 in de handreiking van Atria en ProDemos (2018) om meer vrouwen in de lokale democratie vertegenwoordigd te zien.

Tot slot de rol van politieke partijen. Zij kunnen duidelijk maken dat ze diversiteit nastreven, op welk niveau van bestuurlijk Nederland dan ook. Zij kunnen ervoor zorgen dat de vacatureteksten voor bijvoorbeeld wethouders genderneutraal zijn, dat de gebruikte termen zowel mannen als vrouwen aanspreken. Er is ook op dit vlak duidelijk een taak weggelegd voor politieke partijen.

\section{Maak de wegen vrij door coaching en begeleiding}

Coaching en begeleiding worden gezien als effectieve manieren om meer vrouwen en etnische diversiteit in de lokale politiek en in overheidsmanagement te krijgen en te houden. Het persoonlijk en gericht benaderen van vrouwen voor het ambt en het inzetten van rolmodellen blijken daarnaast de diversiteit te bevorderen (Van Egten e.a., 2016). De huidige commissarissen van de Koning en ervaren bestuurders kunnen het tij keren en wegen vrijmaken voor vrouwen, mensen met een migratieachtergrond of jongeren. Zij kunnen het goede voorbeeld geven en minimaal één persoon die tot deze groepen behoort coachen en begeleiden naar een positie in het openbaar bestuur. Want bestuurders dragen niet alleen de verantwoordelijk voor goed bestuur nu, ze zouden dat ook moeten ambiëren voor de periode dat ze geen bestuurder meer zijn. Deze methode geldt net zo goed voor andere sectoren, zoals de politiek, de politie, de academische wereld. Persoonlijke begeleiding geeft toekomstige ambtsdragers enerzijds inzicht in de mores van het ambt en biedt hun de mogelijkheid zich te ontplooien en te equiperen met de nodige vaardigheden. Anderzijds vergroot het de kweekvijver voor dergelijke functies. Deze vijver wordt groter naarmate we intensiever streven naar meer vrouwen in de politiek. Denk aan het actief stimuleren van de participatie van vrouwen in de gemeenteraden. Of aan vrouwelijke wethouders die zodanig aan de weg timmeren dat zij later andere bestuurlijke of politieke functies kunnen vervullen. Gerichte benadering en begeleiding vergroot op den duur het potentieel aan vrouwen voor bestuurlijke posities. De huidige kandidatenprogramma's voor burgemeesters en wethouders kunnen daarop inspelen: zij kunnen persoonlijke coaching door de huidige bovenbazen in het openbaar bestuur introduceren. Want elk glazen plafond, ook voor gekleurde mensen, kun je het gemakkelijkst van bovenaf kapotslaan. Als dat gebeurt, dan ziet de foto van bestuurlijk Nederland er binnen afzienbare tijd anders uit. 


\section{Tot besluit}

Minister Ollongren wil graag de man-vrouwverhouding in het openbaar bestuur in balans brengen. Haar streven is dat in de toekomst vrouwen tussen de 40 en 60 procent van de functies in politiek en bestuur bekleden. Dat is ook logisch, want we zijn met evenveel vrouwen als mannen in de Nederlandse samenleving en dat zouden we terug moeten zien in het openbaar bestuur. Hoe meer vrouwen en etnische diversiteit in politiek en bestuur, hoe meer perspectief we creëren voor jongere generaties. Vrouwen en personen met een migratieachtergrond in het openbaar bestuur fungeren als rolmodellen en tonen aan jonge mensen dat het voor iedereen mogelijk is een dergelijke functie te bekleden. De praktijk leert ons dat het vergroten van de aantrekkingskracht van leidinggevende posities voor vrouwen in bijvoorbeeld de zakenwereld, bij de politie, bij de rijksoverheid en in de universiteitswereld helpt om het openbaar bestuur diverser te maken.

Maar het is niet eenvoudig om vrouwen of mensen met niet-Nederlandse wortels op te nemen in publieke organisaties die traditioneel nogal 'wit' en 'mannelijk' zijn. Van bovenaf vertellen dat zowel vrouwen als etnische groepen gewenst zijn, is niet voldoende. Quota leiden bovendien vaak tot ongemak en verzet. Uit diverse trajecten weten we dat een financiële stimulans een effectief middel kan zijn om een duurzame beweging te laten ontstaan. De twee NWO-programma's 'Mozaïek' en 'Women In Science' - hebben dit bewezen: Zo hebben er meer mensen met een niet-Nederlandse achtergrond een wetenschappelijke positie kunnen krijgen aan de universiteiten, en stromen er vaker dan voorheen vrouwen door naar hogere posities in de wetenschap. Dit laat zien dat het argument 'ze (= hoogopgeleide vrouwen en etnische minderheden) zijn er niet' niet meer opgaat. Voor meer diversiteit in publieke organisaties maar ook in de politiek-bestuurlijke functies kan een financiële prikkel dus helpen. Dat kan door bijvoorbeeld aan besturen, directies van organisaties en eventueel ook politieke partijen het volgende toe te zeggen: 'Voor elke drie vrouwen of personen met een migratieachtergrond die je vanaf nu aanstelt, krijg je één extra vrij te besteden fte.'

Dit is belangrijk, want het aandeel etnische diversiteit in het openbaar bestuur is alarmerend laag. Dat blijkt uit de cijfers van tabel 1. Opvallend is dat bij direct door de burger gekozen politici, zoals Tweede Kamerleden (13 procent) en raadsleden (naar schatting tussen 6 en 13 procent), wél een representatie te zien is van de etnische diversiteit van de samenleving. Daar waar de burger geen directe invloed heeft, zoals bij commissarissen der Koning, burgemeesters en wethouders staan de percentages op nul of iets daarboven. Als etnische diversiteit en in het bijzonder vrouwen van niet-Nederlandse origine expliciet niet worden meegenomen in de pogingen van minister Ollongren om meer vrouwen in het openbaar bestuur te krijgen, dan is dat een gemiste kans.

Overigens is er ook in het algemeen nog werk aan de winkel als het gaat om vrouwen in het openbaar bestuur. Uit de Global Gender Gap Index van het World Economic Forum (2019) is gebleken dat er sprake is van ongelijkheid tussen mannen en vrouwen in Nederland. Nederland is elf plaatsen gedaald op de ranglijst en bevindt zich nu op plaats nummer 38. Een verklaring voor deze achteruitgang is 
dat Nederland het op het gebied van genderdiversiteit in de politiek slechter is gaan doen. Zo wordt slechts 33 procent van de zetels in de Tweede Kamer en 39 procent van de ministersposten door vrouwen bekleed. De geringere representatie van vrouwen in de media ondersteunt deze verklaring. Het aandeel vrouwen in Nederlandse non-fictie televisieprogramma's, bijvoorbeeld, is 36,6 procent (Commissariaat voor de Media, 2019).

Het is dringend gewenst stagnatie in gender en etnische diversiteit in politiek en bestuur te voorkomen. De afgelopen dertig jaar zijn er tal van maatregelen genomen. De hamvraag is welke maatregelen wel (enig) effect hebben gesorteerd en welke minder. Dit vergt nader onderzoek. De kunst is om daar lessen uit te trekken en niet opnieuw het wiel te gaan uitvinden. Dit artikel beschrijft enkele van deze lessen. Verder is het nodig kritisch te kijken naar de veranderende profielen voor politieke bestuurders en de bijbehorende werving-en-selectieprocedures. Maar nog belangrijker is de bereidheid van de huidige top van bestuurlijk en politiek Nederland om vrouwelijke en kleurrijke talenten te scouten en te begeleiden, opdat die in de toekomst hun rol kunnen overnemen. De tijd is aangebroken om dit vraagstuk serieus aan te pakken: ja zeggen en echt doen. Immers, we kunnen er niet omheen dat diversiteit in de samenleving en op de arbeidsmarkt een spijkerhard feit is.

\section{Literatuur}

Akachar, S. (2019). Diversiteit in de Raad: Bekend maar soms onbemind. Perspectieven en visies van gemeenteraadsleden op het belang van diversiteit in de Raad. Amsterdam: Vrije Universiteit Amsterdam.

Algemene Rekenkamer (2019). Diversiteit in vaste adviescolleges van de regering. Den Haag: Algemene Rekenkamer.

Artria, \& ProDemos (2018). Meer vrouwen in de gemeenteraad. Tips \& tricks voor kandidatencommissies. Amsterdam/Den Haag: Artria/ProDemos.

BZK (2016). Staat van het Bestuur 2016. Den Haag: Ministerie van Binnenlandse Zaken en Koninkrijksrelaties.

Çelik, S. (2014). Van doelgroepenbeleid naar business case van diversiteit: de invloed van het kabinet op publieke sectoren. Bestuurswetenschappen, 68 (4): 5-33.

Çelik, S. (2016). Sturen op verbinden. De business case van diversiteit binnen de publieke sector (proefschrift). Leiden: Universiteit Leiden.

Çelik, S. (2018). Diversiteit in bestuurskundig perspectief. Bestuurskunde, 27 (4): 67-78.

Çelik, S., \& Hopman, N. (2018). Leiderschapsdilemma's van burgemeesters in tijden van verandering. Bestuurswetenschappen, 72 (3): 59-66.

Commissariaat voor de Media (2019). Representatie van mannen en vrouwen in Nederlandse non-fictie televisieprogramma's (onderzoeksrapport in opdracht van het ministerie van Onderwijs, Cultuur en Wetenschap). Hilversum: Commissariaat voor de Media.

Egten C. van, Hekke, J. van het, Post, L., Jong, T. de, \& Jansen, A. (2016). Vrouwenstemmen in de raad. Belemmeringen en successen van vrouwen in de lokale politiek. Amsterdam: Artria, Kennisinstituut voor Emancipatie en Vrouwengeschiedenis.

Ely, R.J., \& Thomas, D.A. (2001). Cultural Diversity at Work: The Effects of Diversity Perspectives on Work Group Processes and Outcomes. Administrative Science Quarterly, 46 (2): 229-273. 
Giskens, F. (2019). Toespraak discussieforum over diversiteit in vaste adviescolleges van de regering, 12 december. Den Haag: Algemene Rekenkamer.

Herschberg, C. (2019). Through the gate of the neoliberal academy. The (re) production of inequalities in the recruitment and selection of early-career researchers (proefschrift). Nijmegen: Radboud Universiteit Nijmegen.

Jong, E. de, \& Leyenaar, M. (2019). 100 jaar vrouwenkiesrecht. Een tussenstand (onderzoek naar deelname van vrouwen in het openbaar bestuur met een focus op gemeenteraden, wethouders, provinciale staten, gedeputeerde staten, parlement en regering). Den Haag: Raad voor het Openbaar Bestuur.

Jongen, E., Merens, A., Ebregt, J., \& Lanser, D. (2019). Vrouwen aan de Top. Den Haag: Centraal Planbureau/Sociaal en Cultureel Planbureau.

Kaiser, C.R., Major, B., Jurcevic, I., Dover, T.L., Brady, L.M., \& Shapiro, J.M. (2012). Presumed fair: Ironic effects of organizational diversity structures. Journal of Personality and Social Psychology, 104: 504-519.

Kool-Smit, J.E. (1967). Het onbehagen bij de vrouw. De Gids, 130 (9/10): 267-281.

ROB (Raad voor het openbaar bestuur) (2016). Niet alleen een ambt, ook een ambacht. De kwaliteiten van raadsleden, burgemeesters en wethouders. Den Haag: Rob.

SER (2019). Diversiteit in de Top. Tijd voor versnelling. Den Haag: Sociaal Economische Raad.

Sowa, J.E., \& Selden, S.C. (2003). Administrative discretion and active representation. An expansion of the theory of representative bureaucracy. Public Administration Review, 63 (6), 700-710.

Shore, L.M., Cleveland, J.N., \& Sanchez, D. (2018). Inclusive workplaces: A review and model. Human Resource Management Review, 28 (2): 176-189.

Weel, I. (2019, 29 december). 'Er is nog flink werk aan de winkel.' SER-voorzitter Mariëtte Hamer over quotums, topvrouwen en koffiedames. Trouw.

World Economic Forum (2019). Global Gender Gap Report 2020. Genève: WeForum. 